\title{
Vacinas: Da Saúde Pública ao Big Business
}

\author{
Vaccines: From Public Health to Big Business
}

Reinaldo Guimarães (https://orcid.org/0000-0002-0138-9594) ${ }^{1}$

${ }^{1}$ Núcleo de Bioética e Ética Aplicada, Universidade Federal do Rio de Janeiro. R. Venceslau Brás 71, Campus Praia Vermelha, Botafogo. 22290-140 Rio de Janeiro RJ Brasil. gmail.com

\begin{abstract}
The text presents and discusses the main aspects related to the current dynamics of the vaccine industry in the world and in Brazil, focusing on the demand created by the pandemic of COVID-19. At the global level, it briefly exposes the place currently occupied by Brazil within the scope of the BRICS and sets out and analyzes the options - identities and differences - of industrial policy in Brazil, China and India in the field of vaccines. Next, it analyzes the displacement of the vaccine industry, from a situation of exclusive production of immunizers to a majority control by the large pharmaceutical industry. Further on, it recovers recent fundamental aspects of the vaccine industry in Brazil, with an emphasis on Biomanguinhos / Fiocruz and the Butantan Institute. Finally, it discusses the successes and limitations of the technology transfer mechanism used by the two institutions, as well as the relevance of their historically assumed commitment to public health policies.
\end{abstract}

Key words Vaccines, Industrial policy, Patents, BRICS
Resumo O texto apresenta e discute os principais aspectos relacionados à dinâmica atual da indústria de vacinas no mundo e no Brasil, com foco na demanda criada pela pandemia da COVID-19. No plano global, expõe brevemente o lugar ocupado atualmente pelo Brasil no âmbito dos BRICS e expõe e analisa as opções - identidades e diferenças - da política industrial de Brasil, China e Índia no campo das vacinas. A seguir, analisa o deslocamento da indústria de vacinas de uma situação de produção exclusiva de imunizantes para um controle majoritário da grande indústria farmacêutica. Mais adiante, recupera aspectos fundamentais recentes da indústria de vacinas no Brasil, com ênfase em Biomanguinhos/Fiocruz e no Instituto Butantan. Finalmente, discute os sucessos e limitações do mecanismo de transferência de tecnologia utilizado pelas duas instituições, bem como a relevância do compromisso historicamente assumido pelas mesmas com as políticas públicas de saúde. Palavras-chave Vacinas, Politica industrial, $\mathrm{Pa}$ tentes, BRICS 
Vaccines

With the exception of safe water, no other modality, not even antibiotics, has had such a major effect on mortality reduction... ${ }^{1}$

\section{Introdução}

A literatura disponível sobre a dinâmica global no mercado e as políticas nacionais no terreno das vacinas oferece a nós, brasileiros, uma sensação de desconforto. Na primeira década e meia deste século, importantes publicações de corte acadêmico ou não exaltavam os chamados "mercados emergentes” do qual éramos parte. Estes mercados seriam novos atores políticos, tecnológicos e produtivos em vários campos entre os quais o de vacinas, enquanto que os países centrais se aproximavam das estratégias e práticas da indústria farmacêutica global e se afastavam das políticas de saúde pública. A sensação brasileira é de desconforto porque há cerca de cinco anos vamos deixando de ser considerados pelo mundo como um componente ativo desses mercados emergentes, estando cada vez mais descolados de países pertencentes a esse grupo, em particular da Índia e da China. A reorientação política ultraliberal do país que se seguiu a 2016, ao qual se soma agora o agravamento da decadência da indústria brasileira em geral, é o pano de fundo para o nosso tema particular das vacinas, exacerbado pelo terremoto global colocado pela pandemia da COVID-19.

\section{A dinâmica do mercado mundial de vacinas}

Talvez o fato mais relevante ocorrido no panorama farmacêutico internacional nas últimas décadas tenha sido a emergência e atual hegemonia dos medicamentos desenvolvidos por rota biológica, mormente no campo de macromoléculas, em substituição à mais que centenária rota de síntese química. Para as grandes empresas farmacêuticas esse fato colocou um problema e abriu uma imensa oportunidade. O problema foi a escassa competência tecnológica e fabril das farmacêuticas nessa nova rota: a oportunidade foi a descoberta daquela competência na indústria de vacinas. A resultante foi, a partir da década de 1980, o início de um intenso processo de fusões e, principalmente, aquisições de indústrias de vacinas por grandes empresas farmacêuticas ${ }^{2}$. Entre 2005 e 2012, as 13 maiores compras e fusões desse tipo movimentaram cerca de US\$ 220 bilhões e transformaram, em 2012, as farmacêuticas GSK, Sanofi, Pfizer, Merck e Novartis nos maiores produtores globais, então responsáveis por cerca de $75 \%$ do mercado global de vacinas ${ }^{3}$. Atualmente o ranking pode estar modificado, mas o panorama permanece o mesmo. O processo de fusões e aquisições que estamos relatando, entre outras consequências, fez com que as práticas éticas e comerciais da Big Pharma migrassem para a indústria de vacinas, outrora bem mais comprometida com a saúde pública. Acresce a esse deslocamento o fato de que a emergência de novas ameaças epidêmicas, algumas delas incidindo nos países do hemisfério norte, aumentaram as receitas oriundas da comercialização de vacinas. Muito embora o mercado de vacinas seja muito menor do que o de medicamentos (aproximadamente $3 \%$ deste), vacinas tornam-se mais e mais Big Business e pelo que se observa nesta pandemia, essa tendência crescerá.

Ao lado desse processo de oligopolização, a partir de 1994 outro arranjo internacional entrou em cena, dessa vez no campo regulatório. A assinatura do acordo TRIPS, que ocasionou a criação da Organização Mundial do Comércio (OMC), fez com que aumentasse grandemente a dificuldade de livre circulação internacional de conhecimento de base tecnológica, inclusive no campo das vacinas ${ }^{4}$. Nesse terreno, países relevantes para o nosso tema tiveram comportamentos diferentes. O TRIPS concedia um período de dez anos para que cada país pudesse adequar a sua indústria às novas regras. A China ingressou na OMC apenas em dezembro de 2001, a Índia aproveitou integralmente o período de adaptação concedido no acordo (aderiu em 2005) e o Brasil promulgou sua Lei de Patentes em 1996, apenas dois anos depois da aprovação do acordo. Mais ainda, na lei brasileira foram incluídos dispositivos que iam além das obrigações do TRIPS. Essa diferença na decisão política contribuiu também para modular a trajetória das respectivas indústrias nacionais de vacinas nos três países, como se verá adiante.

\section{Brasil, China e Índia}

Para uma exploração do impacto desses dois processos, vale um cotejo da situação da indústria de vacinas no Brasil com dois países de grandes dimensões e que até pouco tempo atrás eram considerados, como o Brasil, economias emergentes e que, por isso mesmo, foram reunidos naquela então novidade denominada de BRICS: a Índia e a China. Qual é a situação do Brasil quanto à disponibilidade de vacinas, a tempo e a hora, dentro e fora de situações emergenciais? O aparecimento de vacinas contra o SARS-CoV-2 numa situação de necessidade aguda colocou 
esse tema no centro das atenções. Penso que vale tanto uma avaliação da atuação dos nossos principais laboratórios públicos produtores quanto um debate sobre a posição do Brasil relativamente à autonomia tecnológica e produtiva do nosso país nesse terreno.

$\mathrm{Na}$ Índia, a política industrial de vacinas, assim como a de medicamentos, foi destinada essencialmente à exportação para os mercados centrais. O sistema de saúde indiano, nos moldes das práticas "ocidentais" até há pouco tempo, alcançava apenas cerca de $25 \%$ da população (1,2\% do PIB) e apenas em 2012 foi iniciada uma reforma do sistema de saúde com vistas a atingir a chamada Cobertura Universal que, todavia, enfrenta enormes dificuldades ${ }^{5,6}$. Parte relevante do sistema de saúde na Índia opera em torno às práticas tradicionais conhecidas como AYUSH (Ayurveda, Unani, Siddha, Naturopatia, Homeopatia e Yoga), para cuja gestão há um ministério específico ${ }^{7}$. A opção pela conquista de mercado externo gerou crescentes associações com empresas multinacionais, o que propiciou um importante fluxo de conhecimento de base tecnológica para a Índia. A parceria entre as empresas globais e indianas nos primeiros tempos deu-se na base de uma divisão de competências, cabendo à Índia a produção dos princípios ativos, a formulação final e a comercialização parcial dos produtos acabados enquanto a Big Pharma continuava responsável pela concepção dos produtos e a manutenção dos respectivos direitos de propriedade intelectual. O impacto da TRIPS no mercado indiano foi muito atenuado em virtude da orientação da política industrial do país, altamente protetiva da indústria local. Essa opção pelo mercado externo foi complementada por uma ligação importante, igualmente externa, com o fornecimento de produtos para a Organização Mundial da Saúde (OMS). Atualmente, dentre as 247 apresentações de vacinas pré-qualificadas pela OMS, 73 são produzidas por laboratórios indianos ${ }^{8}$. A capacidade industrial indiana para vacinas compreendia em 2012, quatro empresas estatais e 17 privadas, sendo uma delas, a Serum Institute of India, a maior produtora mundial de vacinas, lugar que ainda hoje ocupa.

O modelo chinês, no qual a situação do sistema de saúde era parecida com a do sistema indiano, inclusive no que se refere à coexistência de racionalidades tradicionais, em 2009 iniciou uma ampla reforma, também com o objetivo de alcançar a Cobertura Universal ${ }^{9}$. Avaliações independentes sugerem que a reforma alcançou vários objetivos, mas que ainda persistem desafios importantes ${ }^{10}$. A opção de política industrial no campo biofarmacêutico foi a de estimular a criação de empresas privadas mantendo, entretanto, um certo número de empresas estatais como componente estratégico de sua política. Também, diferentemente da Índia, o objetivo primário da política foi atender ao mercado interno em articulação com a reforma do sistema de saúde sem, no entanto, perder de vista o mercado internacional ${ }^{11}$. Em 2010, havia na China 46 plantas industriais produtoras de vacinas, seis estatais, uma público-privada, quatro plantas de empresas multinacionais (GSK [2], Novartis e Sanofi) e 35 plantas privadas chinesas. A política chinesa de vacinas em articulação com a política de saúde possui dois componentes, nos quais uma cesta de vacinas é fornecida gratuitamente a toda a população, fornecida pelos laboratórios estatais, e outra cesta, composta por vacinas mais complexas é fornecida pelos laboratórios privados ${ }^{12}$, contra pagamento direto ou por seguro-saúde.

\section{A indústria de vacinas no Brasil desde a redemocratização}

Vale notar que no Brasil o vínculo entre a política industrial e a política de saúde é anterior à criação do SUS, e que no processo de discussão para sua implementação, tal vínculo foi ponto de debate importante cujo produto mais elaborado foi a construção do Programa de Autossuficiência Nacional de Imunobiológicos (PASNI), de $1985^{13}$. Nele, a orientação das prioridades em termos de vacinas estava intimamente ligada ao Programa Nacional de Imunizações do Ministério da Saúde, criado em 1973 e também fortalecido a partir da inauguração do SUS. O PASNI, imaginado como um programa com atuação no longo prazo, teve sua ação em grande parte anulada pelas características do processo de redemocratização do Brasil, excludente e conciliador. No plano industrial, o programa foi aderente às propostas de abertura comercial indiscriminada, alinhada à globalização produtiva e financeira. Assimm como parte do ímpeto democratizante e generoso do SUS, desbastado entre 1985 e 1990, o PASNI deixou de existir na prática a partir dos governos Collor e Fernando Henrique. Vale registrar iniciativas importantes posteriores, como o Projeto Inovação (Fiocruz, 2002) e o Projeto INOVACINAS (MS, 2006), bem como a presença do complexo industrial da saúde enquanto setor prioritário nas três versões de política industrial elaboradas neste século. Entretanto, a despeito da qualidade das propostas, nada disso foi capaz de mudar radicalmente o quadro brasileiro no campo dos imunobiológicos. 
Segundo a Associação dos Laboratórios Farmacêuticos Oficiais do Brasil (ALFOB), existem quatro produtores de vacinas humanas no Brasil, a saber a Fundação Ataulpho de Paiva, o Instituto de Tecnologia em Imunobiológicos (Biomanguinhos/Fiocruz), o Instituto Butantan e a Fundação Ezequiel Dias (FUNED). Estes quatro laboratórios produzem 16 vacinas, quase integralmente fornecidas ao Programa Nacional de Imunizações. Dessa cesta de produtos, Biomanguinhos contribui com oito, Butantan com seis e Funed e Ataulpho de Paiva com uma vacina cada. Biomanguinhos produz ainda duas variedades do biofármaco eritropoietina ${ }^{14}$. O BCG nacional resultou de tecnologia desenvolvida localmente (1927) e a vacina contra a Febre Amarela teve a tecnologia cedida pela Fundação Rockefeller (1937). As vacinas dupla bacteriana (DT), a tríplice bacteriana (DTP) e a vacina contra a Hepatite B tiveram desenvolvimento e produção locais no Instituto Butantan. Todos os demais produtos foram desenvolvidos, aperfeiçoados e produzidos localmente mediante processos de transferência de tecnologias de laboratórios estrangeiros previstos nos contratos de compra dos produtos para uso exclusivo no sistema público de saúde. Os vendedores das tecnologias foram dois laboratórios franceses, dois cubanos, seis britânicos, dois norte-americanos e um suíço ${ }^{15}$.

As atuais dificuldades do Brasil na obtenção de vacinas contra o SARS-CoV-2 vêm estimulando mais uma vez o debate sobre a necessidade, se não da soberania, no mínimo da autossuficiência nacional no campo das vacinas. $\mathrm{O}$ debate possui várias vertentes, com destaque para a dependência do país nos insumos ativos (IFAS). Reconhecendo a importância do debate sobre a autossuficiência, bem como a ênfase na dependência dos IFAS, torna-se essencial acrescentar a ele o tema das relações entre a indústria brasileira de vacinas e a política pública de saúde. Considera-se que a configuração do nosso parque industrial de vacinas foi construída sobre essas relações, que por sua vez geraram os seus sucessos, dificuldades e desafios remanescentes.

Como já mencionado anteriormente, quando se compara as opções de China e Índia com a brasileira no terreno das vacinas em termos de sua relação com a política de saúde, temos três estratégias distintas que, em resumo e a grosso modo poderiam ser assim descritas: a indiana, na qual a política industrial desenvolveu-se integralmente ao largo da política de saúde, a brasileira, onde a política industrial foi governada pela política pública de saúde e a chinesa, que escolheu um caminho intermediário, valorizando o vínculo com o sistema de saúde ao mesmo tempo mirando o mercado externo, em particular com relação às matérias-primas.

\section{A transferência de tecnologia como estratégia de autossuficiência e o vínculo com o sistema público como estratégia de política de saúde}

O mundo tem testemunhado grandes avanços no campo das tecnologias para a produção de vacinas. Ao lado das tecnologias tradicionais de produção mediante de vírus atenuados e inativados, nas últimas décadas vêm sendo desenvolvidas vacinas baseadas em plataformas, entendidas como vacinas que utilizam um carreador como um ácido nucleico, um vetor viral ou um lipossoma que, de alguma forma, interagem com um alvo antigênico do patógeno em questão ${ }^{16}$. No plano das tecnologias envolvidas, tanto o Butantan quanto Biomanguinhos dominam aquelas mais tradicionais e o desafio mais importante nesse aspecto é uma entrada nesse novo universo das vacinas baseadas em plataformas. Nessa conjuntura da COVID-19, o Butantan escolheu desenvolver um produto cuja tradicional tecnologia (vírus inativado) ele domina há muito tempo. Biomanguinhos escolheu outro caminho, o de apostar em produto baseado em plataforma (vetor viral), cuja tecnologia terá que dominar a partir de agora. Em outros termos, a escolha do Butantan privilegiou a minimização do risco tecnológico e produtivo, enquanto Biomanguinhos privilegiou a possibilidade de entrar em uma rota tecnológica mais moderna, embora com maiores riscos para o domínio completo da tecnologia.

De qualquer modo, como mencionado anteriormente, as duas instituições, na maior parte de seus sucessos, têm baseado sua atividade tecnológica e produtiva na estratégia de transferência de tecnologia e o principal elemento envolvido nessa história é o vínculo estreito das duas com o sistema público de saúde. Além do prestígio internacional de ambas, a grande demanda do Programa Nacional de Imunizações é que tornou atrativa para os detentores das tecnologias a venda de seus produtos com cláusulas de compensação tecnológica, o que propiciou boa parte de sua capacitação nesse terreno. Entretanto, esse importante mecanismo apresenta várias e já conhecidas dificuldades, além de um esgotamento que será sinérgico com as inovações tecnológicas ora observadas no campo vacinal. Os problemas tradicionais são, entre outros, a possibilidade de transferência de tecnologias obsoletas sempre que o contrato não prever atualizações, e a não transferência de toda a tecnolo- 
gia, deixando o recipiente em permanente subordinação ao vendedor e a limitação de mercados e de preços para o produto produzido localmente. A razão do provável futuro estreitamento desse caminho é que as novas tecnologias baseadas em plataformas em muitos casos não estarão à venda como compensação à compra dos produtos acabados. Não apenas por razões comerciais, como também pelas dificuldades técnicas envolvidas em uma eventual transferência ${ }^{17}$. Assim, para as vacinas, a saída tecnológica e fabril observada no caso dos medicamentos genéricos estará interditada, como foi no caso dos medicamentos biológicos. Portanto, esses obstáculos tradicionais e futuros postos à frente da estratégia historicamente preferencial de Biomanguinhos e Butantan precisará ser relativizada, ou melhor dizendo, complementada por outros caminhos.

Se os caminhos tradicionais de estratégias de desenvolvimento de vacinas se estreitam, decorre que uma aproximação da situação de autossuficiência entra na ordem do dia e, para tanto, a inserção no campo das vacinas modernas vinculadas a plataformas deverá ser trilhada com maior intensidade. Com isso, uma nova ordem de desafios se coloca. Os vacinologistas costumam utilizar os termos upstream e downstream para organizar temporalmente o desenvolvimento e produção, aquele dizendo respeito às etapas mais precoces do processo e este as mais tardias. Frente à necessidade de imaginarmos produtos criados e desenvolvidos de modo autóctone, é necessário delimitar até onde vai a responsabilidade direta de Butantan e Biomanguinhos nas etapas mais upstream do desenvolvimento, isto é, definir em que ponto uma fábrica passa a ser responsável por conduzir o processo. Uma história brasileira de sucesso ilustra este ponto.

Entre 2002 e 2004 uma série de decretos foram assinados para obrigar os bancos de sangue a instalar testes moleculares que identificassem contaminação pelos vírus HIV e Hepatite C nas bolsas. Para o desenvolvimento desse teste foi formado um consórcio entre o Instituto de Biologia Molecular do Paraná (IBMP/Fiocruz-PR), a UFRJ e Biomanguinhos para desenvolverem o produto no país. Após alguns anos de trabalho em bancada, em 2009 foi inaugurada uma planta no IBMP para produzir os componentes de biologia molecular do kit. O produto foi escalonado e produzido industrialmente em Biomanguinhos, obteve registro na ANVISA em 2010 e hoje é utilizado largamente na rede de hemocentros ${ }^{18}$. O projeto foi imaginado no país, o trabalho de bancada também, a produção de componentes em condições de boas práticas idem. Apesar de presente desde o início, Biomanguinhos liderou o processo apenas na etapa de escalonamento e produção industrial. O que se retira desse caso de sucesso é que as etapas mais upstream não estiveram com Biomanguinhos, mas sim com grupos de pesquisa de bancada que trabalhavam com boas práticas desde o início. E, deve ser observado que houve componentes importados, mas o centro do projeto, sua concepção, foi $100 \%$ autóctone. Este é apenas um exemplo de prática de desenvolvimento local que poderia ser trilhado pelos nossos dois institutos, com a observação essencial que haverá sempre etapas precoces de desenvolvimento que não dependerão de Butantan ou de Biomanguinhos, mas de grupos de pesquisa que estão localizados em outras instituições, mormente universidades e institutos de pesquisa.

Os últimos parágrafos enfatizaram a necessidade de um ajuste nas estratégias de capacitação tecnológica e produtiva. Entretanto, há outra dimensão, mencionada acima como uma estratégia de saúde pública, essencial tanto para os dois institutos quanto para o sistema de saúde. Como anotado anteriormente neste texto, as relações entre as indústrias de vacinas e os sistemas públicos de saúde quando comparamos Brasil, Índia e China têm sido bastante diferentes. Enquanto esta adotou uma posição intermediária, Índia e Brasil optaram por estratégias $100 \%$ distintas e opostas. No Brasil, a existência dos dois institutos produtores sempre esteve intimamente articulada com as políticas de saúde pública. Talvez fosse correto dizer que nas últimas décadas a razão da existência deles foi a política pública de saúde. $\mathrm{Na}$ Índia, pelo contrário, a debilidade dessa política levou os fabricantes de vacinas a outros mercados, certamente mais rentáveis, porém em grande débito com a saúde dos cidadãos e cidadãs indianos. Algumas análises têm comentado a opção brasileira sugerindo que ela teria tido como resultante um déficit organizacional e de gestão e que essa diferença é que explica o maior sucesso da experiência indiana no desenvolvimento e produção de vacinas. Haverá sempre espaço para melhorias organizacionais e de gestão e elas devem ser implementadas. Entretanto, essas abordagens microeconômicas nas instituições não deveriam ferir essa relação estratégica entre os dois institutos e a política pública de saúde. Por outro lado, é importante ressaltar outras diferenças de condução política entre os dois países, como por exemplo no tratamento das respectivas políticas de propriedade intelectual aqui já mencionadas. A adesão incondicional e precoce do Brasil às regras do TRIPS retirou graus de liberdade no manejo de uma política de propriedade intelectual que fosse mais adequada às atividades do Butantan e de Biomanguinhos. 


\section{Referências}

1. Plotkin S, Orenstein W, Offit P. Vaccines, 5th ed. Saunders; 2008.

2. Blume S. The erosion of public sector vaccine production: the case of the Netherlands in the politics of vaccination. Manch Openhive [serial on the Internet] 2017 [cited $2021 \mathrm{Feb} 14$ ]; s/v: 148-173. Available from: https://www.manchesteropenhive.com/view/9781526 110916/9781526110916.00014.xml

3. Kaddar M. Global Vaccine Market Features and Trends [Internet]. 2017. World Health Organization [cited $2021 \mathrm{Feb} 18]$; s/v: 148-173. Available from: https:// www.who.int/influenza_vaccines_plan/resources/session_10_kaddar.pdf?ua $=1$

4. Milstien JB, Gaulé P, Kaddar M. Access to vaccine technologies in developing countries: Brazil and India. Vaccine [serial on the Internet]. 2007 [cited $2021 \mathrm{Feb}$ 18]; 25:7610-7619. Available from: https://dcvmn. net/IMG/pdf/access_vaccine_technologies_developing_countries_india_brazil_2007.pdf

5. Mazumdar S. Now more than ever: considering health system reforms in the post-COVID 19 scenario. Indian Labor Econ [serial on the Internet]. 2020 [cited 2021 Feb 18]; 63:157-162. Available from: https://link. springer.com/article/10.1007/s41027-020-00272-z

6. Kumar R. Healthcare and medical education reforms in India: what lies ahead? J Family Med Prim Care [serial on the Internet]. 2013 [cited 2021 Apr 18]; 2(2): 123-127. Available from: https://www.ncbi.nlm.nih. gov/pmc/articles/PMC3894029/

7. Anonymous. Summary of all-India ayush infrastructure facilities 2014. Available from: https://main. ayush.gov.in/sites/default/files/Summary.pdf

8. World Health Organization (WHO). List of Prequalified Vaccines (2020-2021) [internet]. Geneva: WHO; 2021. [cited 2021 Jan 20]. Available from: https://extranet.who.int/pqweb/vaccines/list-prequalified-vaccines

9. Yip W, Fu H, Chen AT, Zhai T, Jian W, Xu R. 10 years of health-care reform in China: progress and gaps in Universal Health Coverage. Lancet [serial on the Internet]. 2019 [cited 2021 Jan 04]; 394(Issue 10204):1192-1204. Available from: https://www.thelancet.com/journals/ lancet/article/PIIS0140-6736(19)32136-1/fulltext\#: :text=Related $\% 20$ Specialty\%20Collections-,Summary, quadrupled $\% 20$ its $\% 20$ funding $\% 20$ for $\% 20$ health

10. China's health-care reform: an independent evaluation [editorial]. The Lancet [serial on the Internet]. 2019 [cited 2021 Jan 04]; 394:1113. Available from: www. thelancet.comVol394September28,2019. https://www. thelancet.com/action/showPdf?pii=S0140-6736\% 2819\%2932210-X

11. Hendricks J, Liang Y, Zeng B. China's emerging vaccine industry. Human Vaccines [serial on the Internet]. 2010 [cited 2021 Jan 4] 6(7):602-607. Available from: https://www.dcvmn.org/IMG/pdf/hendriks_hv_china_vaccines.pdf
12. Zhu N, X Xiao. Vaccines administration law in China [internet]. Lexology [serial on the Internet]. s/d [cited 2021 Jan 4]. Available from: https://www. lexology.com/library/detail.aspx?g=755626dd9758-4a0f-8433-337669580934

13. Buss PM, Temporão JG, Carvalheiro JR, organizadores. Vacinas, soros e imunizações no Brasil [online]. Rio de Janeiro: Editora Fiocruz; 2005 [cerca de 420 p.] [acessado 2021 Jan 4]. Disponível em: http://books.scielo. org/id/wmw76/epub/buss-9788575416068.epub.

14. Associação dos Laboratórios Farmacêuticos Oficiais do Brasil (ALFOB) 2014 [acessado 2021 jan 04]. Disponível em: http://alfob.org.br/produtos-vacinas/

15. Luchese MD, Bertolini SR, Moro AM, Larentis AL. Dependência tecnológica na produção de imunobiológicos no Brasil: transferência de tecnologia versus pesquisa nacional. Univ Soc 2017 [acessado $2021 \mathrm{fev} \mathrm{12]} \mathrm{\# 59:}$ 46-54. Disponível em: https://www.researchgate.net/ publication/313698334_Dependencia_tecnologica_ na_producao_de_imunobiologicos_no_Brasil_transferencia_de_tecnologia_versus_pesquisa_nacional

16. Johns Hopkins Bloomberg School of Public Health. Vaccine Platforms: state of the field and looming challenges 2019. [cited 2021 Feb12]. Disponível em: https://www. centerforhealthsecurity.org/our-work/pubs_archive/ pubs-pdfs/2019/190423-OPP-platform-report.pdf

17. Ho PL, Miyaji EN, Oliveira MLS, Dias WO, Kubrusly FS, Tanizaki MM, EAL Martins, I Raw. Economical value of vaccines for the developing countries - the Case of Instituto Butantan, a public institution in Brazil. PLoS Negl Trop Dis [serial on the Internet]. 2011 [cited $2021 \mathrm{Feb} 12$ ]. 5(11):e1300. Available from: https:// www.ncbi.nlm.nih.gov/pmc/articles/PMC3226538/

18. Kameda K, Corrêa MCDV, Cassier M. A incorporação do teste diagnóstico baseado na amplificação de ácidos nucleicos (NAT) para triagem de sangue no SUS: arranjos tecnológicos para a nacionalização do "NAT brasileiro". Physis [serial on the Internet]. 2018 [acessado 2021 fev 12]; 28(1):e280108. Disponível em: http://www.scielo.br/scielo.php?script=sci_arttext \&pid=S0103-73312018000100405

Artigo apresentado em 04/02/2021

Aprovado em 05/02/2021

Versão final apresentada em 10/02/2021

Editores-chefes: Maria Cecília de Souza Minayo, Romeu Gomes, Antônio Augusto Moura da Silva 